This is the version of the book review that was accepted for publication in Public Administration, all rights reserved.

Please cite as: Pattyn, V. (2019), Customized implementation of European Union food safety policy: United in diversity? Public Administration. doi:10.1111/padm.12601

\title{
CUSTOMIZED IMPLEMENTATION OF EUROPEAN UNION FOOD SAFETY POLICY. UNITED IN DIVERSITY?
}

\section{Eva Thomann}

London, Palgrave MacMillan, 2019, 228p., Hardcover, £54.99, ISBN: 978-3-319-92683-4

'United in diversity' has been the central leitmotif driving European integration. The European Union (EU) is particularly anchored in the idea of reconciling integration with doing justice to differences in national preferences. While the tension between discretion and control of policy implementation can be said to be inherent to the nature of the EU, it is only limitedly understood. As Eva Thomann rightly argues, EU policy implementation scholars have been biased towards investigating merely (non-)compliance. However, also when states are legally complying with EU Directives, EU rules frequently undergo a process of vertical regulatory change, resulting in a diversity of domestic solutions to common policy problems. Thomann coins this phenomenon 'customized implementation'. If we conceive the EU as the joint governance of complex cross-border problems, having empirical insight into customization is key. In her book Thomann brings a series of studies together in which she systematically investigates the patterns, causes and consequences of customization in five countries (4 EU member states- France, Austria, UK, and Germany, plus Switzerland) in the field of food safety policy. The book could not have been timelier with the process of European integration being under severe attack.

Thomann's contribution is innovative, not at least in conceptual and methodological terms. With the concept of 'customization', she introduces an empirically more comprehensive and less normative notion than 'gold-plating'. Drawing on the regulatory output literature, customization captures the change that EU rules undergo in both density and restrictiveness during legal transposition, within different categories of policy content. The analysis of customization equally triggers conceptual reflections about the very notion of 'unity in diversity'- the subtitle of the book.

Also in methodological terms, Thomann's research is cutting-edge: she demonstrates the full potential of set theoretic methods to capture the complexity of policy implementation. Throughout the book she presents a state of the art application of different set-theoretic techniques to identify the conditions that yield extensive or limited customization; or successful and unsuccessful implementation. Set-theoretic methods are particularly apt to account for the conjunctural patterns underpinning customization and policy implementation, they can identify different country- and policy-specific conditions that characterize policy implementation patterns (equifinality), and can model asymmetric causality. In the empirical 
chapters, the cross-case comparisons are complemented with a targeted analysis of typical and deviant cases, which also help understanding unexpected patterns. Thomann's application of set-theoretic methods qualifies as best practice in multiple respects. I highlight, for instance, the configurational way in which hypotheses are consistently formulated; and the compellingly comprehensive presentation of the (still relatively complex) set-theoretic findings, also in terms of clear policy advice -being exceptional both for policy implementation and QCA researchers. Academics and policy-makers not familiar with the set-theoretic approach can as such easily grasp the essence.

The evidence about the causes and consequences of customization challenges us to profoundly rethink what 'better regulation' involves, and puts the EU's no gold-plating policy into perspective. As convincingly argued, it would be unwise to avoid over-implementation at all costs. Instead, in some situations, granting discretion to member states can play an important role in successful policy implementation. This turns out to be especially the case for EU policies concerning intractable problems, marked by high political conflict, and/or that are not well thought through, or in certain domestic situations -the latter not being under control of the EU though. Importantly, in certain instances, literal transposition of EU directives can even contribute to practical implementation failures in domestic contexts. The findings further hint at targeted steering mechanisms which would be most effective to govern customization issues, should this be considered appropriate. As an analysis of neo-institutionalist logics underpinning member states' implementation decisions reveals, a distinction is to be made between micro and macro-strategic issues in this regard. The former turn out to be more apt for resorting to communication instruments; while management and enforcement approaches could be fit for macro issues.

Thomann shows clear awareness of the limitations of her research and is very transparent about these. Most of these relate to the case-based nature of the research, which inevitably limits the scope of generalizability of the results. Indeed, it remains to be tested to what extent the results also hold relevance across food safety policy, knowing that policy implementation is predominantly sector specific, and that food safety policy is a case that is likely one for compliant positive transposition. The index of customization does unfortunately not account for the very content or the direction of change, a shortcoming that is also recognized though.

In a similar vein, it is uncertain to what extent the findings hold beyond the relatively homogeneous selection of countries studied. It is unclear, for instance, how the results are affected by the relatively mature administrative tradition of the five countries studied. The book deals with the problem solving capacity of the EU and the role of customization in this regard. The question is, yet, what problem solving capacity is required also at member state level to make customization optimally work. Customization inevitably involves a policy learning component. How should we conceive the cumulative knowledge base that countries develop in this regard, and the regulatory and analytical capacities that this entails? Linked to this, it would be interesting to learn whether and how lessons travel across policy sectors and across member states. Similarly, but this admittedly exceeds the scope of the book, it would have been insightful how customization lessons feed back to the EU. The focus on the mere outcome of customization comes somewhat at the cost of a more dynamic process-based 
understanding of the phenomenon. The study of typical and deviant cases unveils some process related elements, but leaves the very blackbox of actual customization decisionmaking closed. The rather static approach is common to set-theoretic methods, which do not easily help accounting for dynamic and time-related aspects. As a result, it is neither clear how intervention hypotheses that causally link policy outputs to outcomes are to be conceived at domestic level, whether they are well thought through at all, and to what extent these deviate from the intervention logic underpinning EU regulation.

The idea of better regulation is intrinsically normative. Thomann applies a performance oriented lens to it, by measuring the contribution of customization to programmatic success or failure -as such relegating other possible evaluation criteria such as equity, sustainability, or legitimacy to the background. Programmatic success is operationalized as the absence of evidence of implementation problems at domestic output and outcome level. With customization resting on a bottom up approach to policy implementation, it can be said that this measurement does not fully capture the country level interpretations of policy success, or the effectiveness of customized country or intra-country intervention logics. Future research ideally complements the findings with a more multilevel conceptualization of policy effectiveness. This being said, the book unequivocally puts regulatory quality in a different perspective, and compellingly calls to seriously consider the role of customization in this context. 